\section{Questión}

Periodismo / Comunicación ISSN 1669-6581
- Av. $44 \mathrm{~N}^{\circ} 676,1^{\circ}$ piso

CP 1900 - La Plata - Argentina

@ww.perio.unlp.edu.ar/question

Museos y pandemia

Andrés Duprat

DOI: https://doi.org/10.24215/16696581e299

\title{
Museos y pandemia
}

\section{Museums and pandemic}

Andrés Duprat / andresduprat@yahoo.com.ar Arquitecto, curador de arte y guionista de cine.

Desde Diciembre de 2015 es Director del Museo Nacional de Bellas Artes de Argentina. Se desempeñó durante 10 años como Director de Artes Visuales del Ministerio de Cultura de Argentina (2005-15). Creó y dirigió el Centro de Arte Contemporáneo Espacio Fundación Telefónica en la ciudad de Buenos Aires (2003). Fue Director del Museo de Bellas Artes de Bahía Blanca y, a partir de su creación en 1995, del Museo de Arte Contemporáneo de esa ciudad. Como curador de arte realizó más de un centenar de exposiciones en museos y centros de arte de Argentina y de Francia, Estados Unidos, China, México, Italia, Cuba, Chile, Rusia, Egipto, España y Japón entre otros. Fue curador del envío Argentino a la Bienal de Arte de Venecia en 2017.

Ha escrito los guiones de los largometrajes "Mi obra maestra", "El ciudadano ilustre","El hombre de al lado", "Querida voy a comprar cigarrillos y vuelvo", "El artista”, "Living Stars" y "Todo sobre el asado" dirigidos por Mariano Cohn y Gastón Duprat con los que ha obtenido reconocimiento internacional.

En las últimas tres décadas del siglo $\mathrm{XX}$ y de modo inexorable ya en el siglo $\mathrm{XXI}$, los museos fueron tomando cada vez más protagonismo en el seno de la sociedad. A su misión original de conservar, estudiar y difundir una colección, fueron sumándose gradualmente nuevos objetivos; sus funciones y usos se han ido resignificando, y su relevancia creció tanto como su poder simbólico.

En poco tiempo, los museos se han transformado en extraordinarios focos de interés en la vida social. Las modernas estructuras arquitectónicas que albergan sus colecciones requirieron una 
renovación de los modos de exhibición. El rol de directores, curadores, investigadores, museógrafos y demás agentes del circuito artístico multiplicó su incidencia en la gestión de las instituciones museísticas. Erguidos como espacios de encuentro e intercambio social, los museos han sido motor del despliegue de múltiples actividades culturales, educativas, lúdicas, turísticas, comerciales y de esparcimiento. Hoy son el centro neurálgico de las grandes urbes, lugares de referencia y representación del interés por la cultura en las diferentes sociedades e insoslayables íconos arquitectónicos que, en ocasiones, definen la identidad de una ciudad o de una nación. La proliferación del turismo internacional, consecuencia de la mayor accesibilidad para viajar, ha hecho de los museos citas obligadas para cualquier viajante, tenga este un particular interés por lo que ofrecen estas instituciones o no. Ya no es posible conocer París sin visitar el Louvre o el Pompidou; Madrid, sin pasar por el Prado o el Reina Sofía, Nueva York sin conocer el MET o el MoMA. Los grandes museos reciben cientos de miles de visitantes, y Buenos Aires no es ajena a ese fenómeno: el Museo Nacional de Bellas Artes es visitado por más de medio millón de personas al año, de los cuales un 30\% representa a turistas de todo el mundo. Es común ver largas filas para ingresar a una exposición, y en algunos museos, incluso, es necesario reservar con antelación entradas para poder acceder a resonantes exhibiciones o a sus colecciones.

La irrupción de una problemática tan compleja y acuciante como el Covid-19, que en esta primera etapa obliga al aislamiento a escala planetaria, ha impactado también en los museos. Cerradas al público, las instituciones han coincidido en la necesidad de buscar nuevas formas de cumplir con su misión al no poder brindar la experiencia de la visita física.

Ante esta situación inédita, han asumido el desafío multiplicando su presencia en las redes sociales y en los medios de comunicación, proponiendo visitas virtuales, proporcionando acceso e información digital sobre sus colecciones, además de cursos y actividades pedagógicas a distancia. Esta labor ha permitido mantener activa cada institución y su conexión con el público, facilitando un acercamiento a las obras de arte centrado en la percepción individual a través de dispositivos digitales. Como es del todo evidente, estos median y formatean la experiencia estética, son herramientas de interpretación y diálogo crítico con las obras, pero son incapaces de sustituir la experiencia en los términos en que venimos describiéndola, cuya condición mínima es la visita física al museo. Entrar a un edificio, caminar y perdernos en sus salas y corredores, detenernos en las obras y objetos que llaman nuestra 
atención, demorarnos en ellos, recorrerlos con la mirada, percibirlos en profundidad, bien expuestos e iluminados, en un ámbito amplio y silencioso que ayuda a que tengamos una experiencia sensible significativa.

La mediación tecnológica nos ofrece una perspectiva posible, pero debilita nuestro rol de espectadores, cancela la espacialidad, borra las texturas, abstrae de nuestra memoria sensorial la acción de nuestra mirada sobre la superficie de las obras. La pantalla nos brinda una idea, invita al concepto, pero no reemplaza la experiencia perceptiva directa, que es singular e intransferible.

La aparición de nuevos dispositivos y lenguajes, como la fotografía, el cine, la televisión e internet, agitó en cada época el fantasma de la pérdida del aura de las obras de arte. Sometida a la posibilidad de la multiplicación infinita, la obra de arte visual (pero también el teatro, la música y cualquier manifestación que requiriera la participación activa del espectador) se veía amenazada en su singularidad y, con ello, en su estatuto artístico. Sin embargo, nada de eso ha sucedido. Más bien, cada una de las nuevas tecnologías permitió abrir un campo artístico alternativo, en diálogo con las disciplinas a las que se suponía que sustituirían. Así como el cine no terminó con la novela ni con el teatro, los dispositivos tecnológicos de la presente época y las posibilidades de circulación que plantea internet han alentado nuevos lenguajes artísticos de gran vitalidad. Pero todos ellos tienen su cifra en la experiencia del espectador, que, como decía Borges y ya es un lugar común, completa la obra. La vida virtual no sustituye la experiencia, aunque es en sí misma un nuevo tipo de experiencia, diferente.

La tecnología nos permite visitar cualquier rincón del planeta a través de un click. Podemos visualizarlo, informarnos, estudiarlo, sumergirnos virtualmente, pero esto no sustituirá todo aquello que podemos ver, hacer y sentir en una visita con nuestra presencia real en un espacio real. Del mismo modo sucede con los vínculos afectivos y sociales. Aunque virtuales, son reales, pero su desarrollo en el terreno de la virtualidad no reemplaza la experiencia fáctica del encuentro humano.

Para reflexionar sobre la situación que plantea esta pandemia al mundo del arte, podemos apelar a la historia, sin desconocer la novedad y anomalía por la que estamos atravesando. Tras cada catástrofe -pestes, guerras, tragedias naturales, caídas de civilizaciones, crisis económicas-, el arte siempre ha podido reconfigurarse, tanto en sus formas, modos de circulación y consumo, como en sus estéticas y funciones. La Venus de Milo o la Victoria de 
Samotracia nos llegan milenios después del fin de la civilización que las sustentaba, y sin embargo, logran comunicarnos, aún en lo que queda de ellas, o precisamente merced a la devastación que padecieron, el espíritu de la cultura helénica. El mayor desafío para el mundo del arte será reinventarse bajo las nuevas condiciones. No sabemos cómo quedará configurada la realidad después de la pandemia, aunque intuimos que dejará secuelas importantes. Y si bien esta pandemia es nueva, no lo es la necesidad de reinvención en el campo del arte, que es finalmente un universo dinámico y en eterna expansión. La revisión de sus parámetros es una constante en la historia. O, podemos decir, es su historia. La historia del arte es la historia de sus múltiples mutaciones. 